
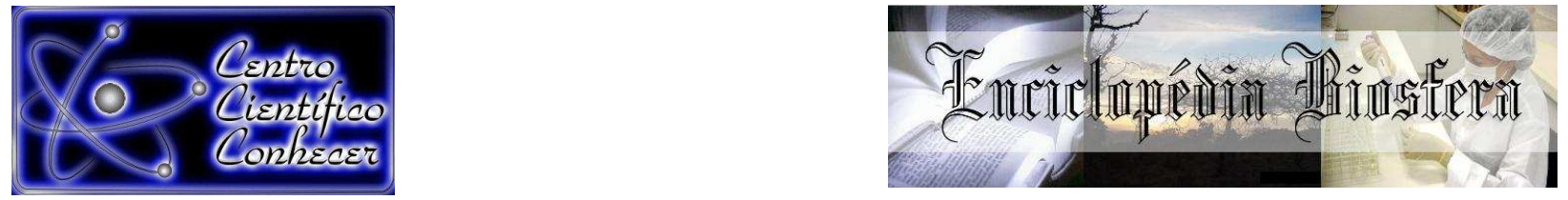

\title{
SILAGEM DE COLOSTRO E LEITE DE TRANSIÇÃO PARA ALIMENTAÇÃO DE BEZERRAS: REVISÃO DE LITERATURA
}

\author{
Ana Priscila Doria ${ }^{1}$, Luciana da Silva Leal ${ }^{2}$, Valquiria Nanuncio Chochel $^{3}$, \\ Andressa Carvalho Neves ${ }^{4}$, Adriana de Souza Martins ${ }^{5}$ \\ ${ }^{1}$ Zootecnista, Grupo MelkStad - Carambeí/PR, Brasil. \\ ${ }^{2}$ Médica Veterinária, Docente do Curso de Zootecnia - UEPG - Ponta Grossa/PR, \\ Brasil. (E-mail: lu_s_leal@yahoo.com.br). \\ ${ }^{3}$ Bióloga e Mestre em Gestão do Território - UEPG - Ponta Grossa/PR, Brasil. \\ ${ }^{4}$ Acadêmica do Curso de Zootecnia - UEPG - Ponta Grossa/PR, Brasil. \\ ${ }^{5}$ Zootecnista, Docente do Curso de Zootecnia - UEPG - Ponta Grossa/PR, Brasil. \\ Recebido em: 03/10/2016 - Aprovado em: 21/11/2016 - Publicado em: 05/12/2016 \\ DOI: 10.18677/EnciBio_2016B_088
}

\begin{abstract}
RESUMO
As melhorias nas técnicas de alimentação e de manejo na exploração leiteira viabilizaram alternativas econômicas para a criação de bezerros. A silagem de colostro ou do leite de transição é uma forma barata de se obter um substituto de boa qualidade nutricional ao leite, que deve ser substituído para diminuir os custos do produtor. O objetivo desta revisão de literatura foi apresentar a silagem de colostro ou do leite de transição como ferramenta para diminuir os custos da produção leiteira, os resultados de desempenho dos animais e os desafios para que essa técnica se fortaleça como um alimento alternativo na dieta de bezerras. A silagem mantém os valores de proteína, matéria seca e gordura do colostro e leite in natura; entretanto, há uma diminuição no teor de lactose pelo processo fermentativo. Silagens com fermentação inadequada apresentam $\mathrm{pH}$ elevado e representam risco de contaminação por microrganismos patogênicos; além de reduzir o tempo de estocagem e a qualidade protéica do alimento. Com relação a performance dos animais que consumiram colostro ou leite de transição fermentados, as conclusões dos experimentos são contraditórias e variáveis, o que pode ser decorrente das características nutricional e microbiana iniciais da secreção láctea e diferentes condições higiênicas de preparo e armazenamento em cada trabalho. No entanto, há uma superioridade dos resultados, quando a silagem é diluída em leite e não em água. Existe um espaço importante para novas pesquisas, pois o emprego da silagem de colostro/ leite de transição representa uma grande economia para a cadeia leiteira.
\end{abstract}

PALAVRAS-CHAVE: acidez, bactérias, bovino, fermentação.

\section{COLOSTRUM AND TRANSITION MILK SILAGE FOR FEEDING CALVES: LITERATURE REVIEW}

\section{ABSTRACT}

Improvements in feeding and management techniques in dairy farm made viable economic alternatives for calves breeding. The colostrum or transition milk silage is a ENCICLOPÉDIA BIOSFERA, Centro Científico Conhecer - Goiânia, v.13 n.24; p.924 
cheap way to get a good milk replacer, the milk should be substitute to reduce producer costs. The aim of this review was to present the colostrum or transition milk silage as a tool to reduce the cost of milk production, animal performance results and challenges for this technique to be strengthened as an alternative food in calves' diet. Silage keeps the protein, dry matter and fat similar values of colostrum and whole milk; however, there is a decrease in the lactose content because of the fermentation process. Silages with inadequate fermentation have high $\mathrm{pH}$ and are a risk of contamination by pathogenic microorganisms; reduce the storage time and the protein quality of the food. Regarding the performance of animals fed colostrum or transition milk fermented, the findings of the experiments are contradictory and variables, which may result from initial nutritional and microbial characteristics of milky secretion and different hygienic conditions for preparation and storage at each research. However, there is a superiority of results when the silage is diluted in milk rather than water. There is an important area for further research, because the use of colostrum/ milk transition silage represents a great economy for the dairy farm.

KEYWORDS: acidity, bacteria, bovine, fermentation.

\section{INTRODUÇÃO}

Sabe-se que, dentre todas as categorias, a fase de cria dos animais é um desafio, pois exige atenção que nem sempre lhe é dada e este fato normalmente ocorre devido às bezerras representarem custos sem retorno em curto prazo. Para SILPER et al. (2012), a criação de bezerras e novilhas representa parte importante dos custos de um sistema de produção de leite, sendo a saúde desses animais fundamental para a criação eficiente.

Em muitas explorações leiteiras, os bezerros são separados de suas mães logo após o nascimento, sendo criados artificialmente o que, infelizmente, representa um grande risco de morbidade e mortalidade (KHAN et al., 2016). A relação entre viabilidade e produtividade na bovinocultura leiteira deve orientar as ações de manejo e buscar a antecipação do desmame, sem interferir no bem-estar e no desenvolvimento das bezerras (AZEVEDO et al., 2013).

Dessa forma, a busca de alternativas para reduzir os custos com a dieta, sem prejudicar o crescimento das bezerras, torna-se fundamental, uma vez que leite ou sucedâneos lácteos comerciais são os componentes mais caros nos custos finais da criação de bezerros (SAALFELD et al., 2013).

O leite destaca-se como uma fonte nutricional completa, por apresentar alto teor de proteínas e sais minerais (LUIZ et al., 2010). De acordo com OLIVEIRA et al. (2010) o leite da fêmea bovina é composto por 3,5\% de proteínas, 3,8\% de gordura, $5,0 \%$ de lactose, $0,7 \%$ de minerais (cinzas) e $87 \%$ de água. Esses valores médios podem apresentar desvios, visto que a variação na composição do leite é grande e, dentre todos os elementos, o que mais altera é a gordura.

Colostro é a primeira secreção láctea produzida após um período seco normal e involução mamária em vacas, ou a primeira secreção láctea de uma novilha (TAHMASBI et al., 2014). O colostro contém diferentes tipos de anticorpos maternos (BATISTA et al., 2016; MALDONADO \& NADER-MACIAS, 2016) e a sua ingestão é fundamental para que os recém-nascidos estejam protegidos na fase inicial de vida (MALDONADO \& NADER-MACIAS, 2016). Além da transferência de imunidade passiva, outra função do colostro é servir como uma fonte alimentar importante de proteínas e lipídios, já que a concentração de lactose é mais baixa em comparação ao leite tradicional (FRANDSON et al., 2011). 
A silagem de colostro ou do leite de transição é uma forma econômica de se obter um substituto ao leite de boa qualidade nutricional para as bezerras em aleitamento, além de diminuir os custos do produtor na criação desta categoria animal (BATISTA et al., 2016). Uma metodologia de armazenamento do colostro em condição anaeróbica foi desenvolvida por SAALFELD (2008) e é chamada de silagem de colostro, que consiste no preenchimento total de garrafas plásticas com colostro, sem espaço para o ar, por um período mínimo de 21 dias.

No entanto, dificuldades na preservação do colostro geram resultados controversos (SAALFELD et al., 2013) e prejudica as características nutricionais do produto final e o desempenho dos animais. Em silagens em que a fermentação foi inadequada, $\mathrm{o} \mathrm{pH}$ não apresenta uma queda efetiva e isso pode manter um ambiente apropriado para a multiplicação de microrganismos patogênicos ou prejudiciais para os animais; além de reduzir o tempo de armazenamento e a qualidade proteica do alimento (AZEVEDO \& DUARTE, 2014; AZEVEDO et al., 2014a).

Diversas pesquisas foram realizadas comparando-se a administração de leite integral, sucedâneo lácteo comercial ou silagem de colostro/ leite de transição, diluída em água ou leite, e o efeito dessas dietas líquidas na performance de bezerros. Contudo, não existe uniformidade de dados publicados na literatura até o momento. Alguns autores defenderam o uso do colostro e do leite de transição fermentados como uma boa alternativa na dieta de bezerros (CASTRO et al., 2004a; MANCIO et al., 2005a; SAALFELD et al., 2008; SAALFELD et al., 2013, VIRGINIO Jr. et al. 2016); outros autores não verificaram eficiência satisfatória no desempenho animal (AZEVEDO et al., 2013; FERREIRA et al., 2013; TAHMASBI et al., 2014). Há ainda aqueles pesquisadores que consideraram que o fornecimento da silagem diluída em leite apresenta resultados próximos ao do leite integral, com a vantagem de representar uma economia nos custos de criação (AZEVEDO et al., 2013; AZEVEDO et al., 2014). A variação nos índices pode ser decorrente da composição nutricional inicial da secreção láctea utilizada para a fermentação, assim como as condições higiênicas de confecção e armazenamento diferentes em cada trabalho.

Independente dos efeitos verificados, a análise econômica aponta que o emprego da silagem diluída em água ou misturada ao leite reduz o custo total da nutrição de bezerras, em comparação ao aleitamento com leite (AZEVEDO et al., 2013).

O objetivo desta revisão de literatura foi apresentar a silagem de colostro ou do leite de transição como ferramenta para diminuir os custos de um sistema de produção leiteira, os resultados de desempenho de animais que consumiram essa dieta líquida e os desafios a serem transpostos para que essa técnica se fortaleça como um alimento alternativo na dieta de bezerras em aleitamento.

\section{DESENVOLVIMENTO}

A exigência pela produção de leite no Brasil tem crescido cada vez mais e, frente a isso, é importante aliar avanços nas práticas de manejo que propiciam o incremento da produtividade, com as pesquisas recentes de comportamento e bemestar animal, pois ambos os aspectos são essenciais para promover a sustentabilidade dos sistemas de criação animal (NASCIMENTO et al., 2013).

A fase de cria dentro da bovinocultura leiteira é um desafio, pois a saúde, o crescimento e a produtividade das bezerras dependem fortemente da nutrição e das técnicas de manejo adotadas (TAHMASBI et al., 2014). Em decorrência disso, 
estratégias que visam aumentar a resistência ao estresse e às doenças devem ser empregadas para a obtenção de bezerras saudáveis (HULBERT \& MOISÁ, 2016).

Deve-se ter um cuidado especial com a fase de cria e recria, pois, neste período ocorre o crescimento corporal rápido que influencia também no desenvolvimento do tecido mamário. Esse evento fisiológico é primordial para assegurar que as fêmeas mais velhas do rebanho sejam substituídas por animais saudáveis e com grande capacidade de produção leiteira. Um dos fatores que mais interfere no crescimento do parênquima das glândulas mamárias antes da puberdade é a nutrição. Pesquisas realizadas entre os anos de 1970 e 1990 mostraram que o crescimento corporal acelerado na fase pré-púbere pode refletir em diminuição da idade ao primeiro estro e ao primeiro parto em novilhas. Apesar do efeito positivo na reprodução, existe um prejuízo no desenvolvimento mamário e na primeira lactação. Se os conhecimentos e as técnicas de manejo nutricionais forem bem aplicados, é possível, em um programa de aleitamento acelerado, conseguir ganhos rápidos de crescimento corporal, sem interferir na funcionalidade do tecido mamário, por não permitir a deposição de gordura nas mamas, assegurando, desta forma, a produtividade futura das fêmeas bovinas (AZEVEDO \& COELHO, 2016).

O colostro é uma secreção produzida pelas vacas, após a parição, que é rica em proteínas, dentre estas as imunoglobulinas, minerais, vitaminas, gordura, sólidos totais e cinzas (ANDRADE et al., 2010), portanto é um alimento indispensável, em especial aos animais recém-nascidos. Segundo BATISTA et al. (2016), o produto obtido na primeira ordenha após o parto é o colostro e, nas ordenhas subsequentes, é produzido o leite de transição, sendo que, somente a partir da oitava semana, se origina o leite.

O colostro contém componentes celulares e fatores imunológicos não específicos (MURRAY \& LESLIE, 2013). A presença de diferentes tipos de imunoglobulinas, sendo as mais importantes: IgM, IgA e IgG (BATISTA et al., 2016; MALDONADO \& NADER-MACIAS, 2016) é essencial para prover a imunidade passiva para os neonatos, uma vez que o sistema imune é imaturo ao nascimento porque os bezerros não recebem anticorpos de suas mães durante a vida intrauterina (MALDONADO \& NADER-MACIAS, 2016).

Considerando-se a distribuição das vilosidades coriônicas pela superfície do córion, a placenta bovina é classificada como cotiledonária. Nesse tipo de placenta, as vilosidades coriônicas se agrupam em rosetas chamadas de cotilédones que se relacionam com as carúnculas endometriais do útero. As estruturas uterinas e coriônicas em conjunto formam junções chamadas de placentomas (ROA et al., 2012).

A placenta também pode ser caracterizada pela histologia. Essa análise se baseia no número de barreiras que se interpõem entre o sangue fetal e o sangue materno, sendo o número máximo de seis: três fetais e três maternas. Os tecidos fetais são os seguintes: epitélio do córion fetal, tecido mesenquimático fetal e endotélio do capilar fetal. Os tecidos maternos são: epitélio da mucosa uterina, tecido conjuntivo materno e endotélio dos capilares maternos. As vacas possuem a placenta sindesmocorial, em que o córion se contata com o tecido conectivo materno, faltando a capa epitelial (ROA et al., 2012). Devido à estrutura da placenta bovina que separa o sangue materno do sangue fetal, um neonato bovino nasce sem imunoglobulinas e depende inteiramente da absorção do colostro para ganhar imunidade e proteção adequadas até desenvolver sua própria imunidade na terceira ou quarta semanas de vida (GODDEN, 2008). 
Sabendo-se que a ingestão das imunoglobulinas colostrais produzidas pelo sistema imune da mãe é necessária para o neonato adquirir proteção imune temporária contra agentes infecciosos do ambiente (FRANDSON et al., 2011), CONNEELY et al. (2014) estudaram a administração de colostro para 99 bezerros de raças leiteiras, na quantidade correspondente a 7,0, 8,5 e 10\% do peso corporal, dentro das primeiras duas horas após o nascimento. Os autores concluíram que 0 fornecimento de colostro na proporção de $8,5 \%$ do peso corporal provê uma grande concentração sérica de imunoglobulina $\mathrm{G}$ nos primeiros três dias de vida $(39,1 \mathrm{~g} / \mathrm{L}$ nas primeiras 24 horas de vida).

Em sistemas convencionais de aleitamento, as bezerras recebem quantidades restritas de leite e começam a ingerir alimento texturizado ou peletizado oferecido ad libitum até poucas semanas após o desmame. Muitos produtores desmamam bezerras em uma idade jovem para reduzir os custos associados com a alimentação de leite ou sucedâneo, mas as bezerras nascem com um rúmen não funcional e inicialmente devem contar unicamente com leite para atender às exigências nutricionais de manutenção e crescimento corporal (KHAN et al., 2016).

Apesar do leite ser um alimento rico e completo, é importante considerar que o volume e a qualidade do mesmo são diretamente influenciados por práticas de manejo, elementos físico-químicos e limpeza do ambiente e durante o procedimento de ordenha. Os níveis de lactose, proteína, gordura, vitaminas e sais minerais caracterizam o produto que, por sua vez, são influenciados pela raça, genética, nutrição e sanidade das vacas. Fatores ligados a individualidade de cada animal, como o tempo de lactação, o escore de condição corporal ou situações de desconforto também são relevantes para a composição do leite (NASCIMENTO et al., 2013).

Atender a dieta das bezerras nem sempre é tão fácil, pois o leite é a fonte mais significativa de renda de uma propriedade leiteira e o uso de sucedâneos pode se tornar inviável dependendo do nível tecnológico e da rentabilidade da propriedade. Portanto, é neste contexto, que o uso do leite não comercializável, que possui alto valor nutricional, pode ser uma boa opção, já que normalmente a quantidade de colostro e de leite de transição produzidos pelas vacas recém-paridas são maiores do que o consumo das bezerras (AZEVEDO et al., 2013; BATISTA et al., 2016) e, na maioria dos casos, o excesso é descartado no ambiente (BATISTA et al., 2016).

O colostro é uma fonte apropriada e viável para a alimentação de bezerros, sendo uma excelente opção como substituto do leite. O colostro apresenta características nutricional e imunológica superiores ao leite e possui a vantagem de não representar custo ao produtor (SAALFELD et al., 2013). Com a evolução da lactação, o colostro é substituído pela secreção de leite, em uma fase de transição, produzindo assim o chamado leite de transição que, assim como o colostro, não tem valor comercial (AZEVEDO et al., 2013).

$\mathrm{Na}$ Tabela 1, mostra-se uma comparação entre a composição média dos teores de: sólidos totais (\%), gordura (\%), proteína (\%), anticorpos (\%), lactose (\%), minerais $(\%)$ e vitamina $A(\mu \mathrm{g} / \mathrm{dL})$ do colostro, do leite de transição e do leite integral de vaca, segundo o número de ordenhas após o parto. Os valores apresentados na Tabela 1 foram publicados por WATTIAUX em 1997. 
TABELA 1 - Composição do colostro, do leite de transição e do leite integral de vaca segundo o número de ordenhas após o parto.

Componentes

Número de ordenhas

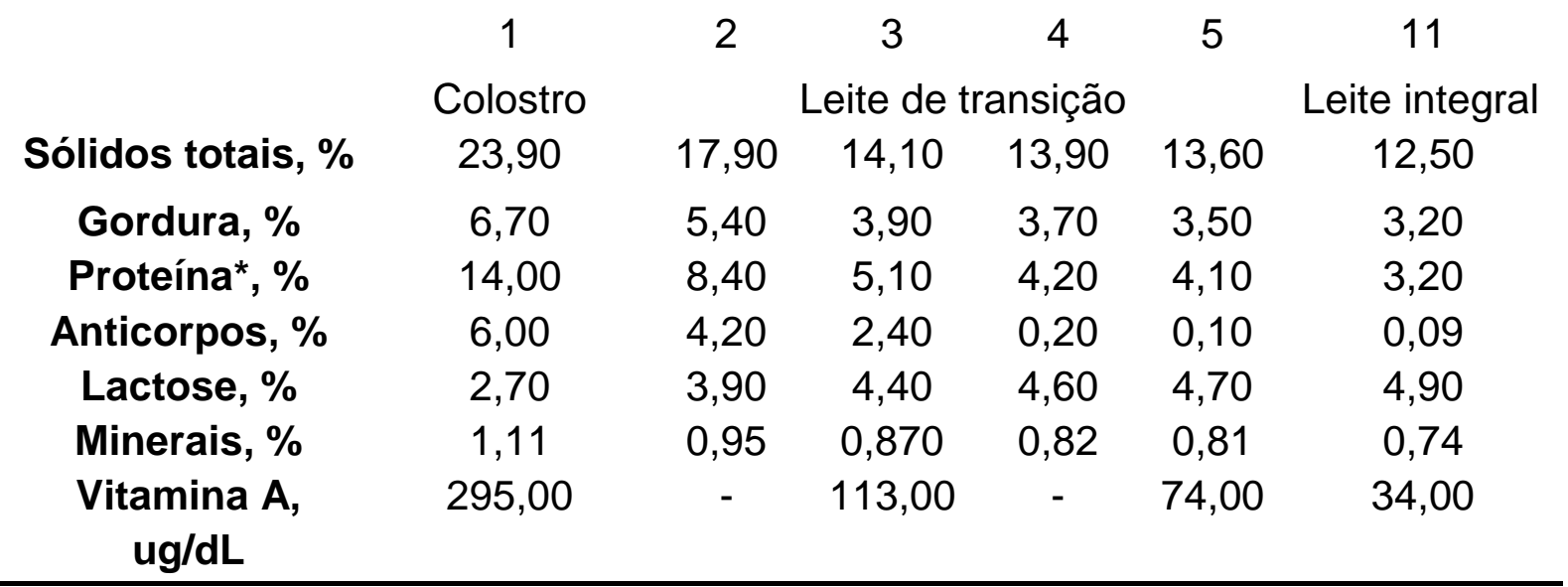

*Inclui percentagem de anticorpos indicados na próxima linha.

Fonte: (WATTIAUX,1997)

Como verificado na Tabela 1, o colostro é uma fonte valorosa de energia para o recém-nascido, pois a maioria nasce com quantidades limitadas de gordura corporal e outras fontes de energia metabólica. As principais fontes de energia no colostro são as proteínas e os lipídios, porque o colostro apresenta uma concentração relativamente baixa de lactose. Deve ser lembrado que a progesterona, que está em concentração elevada no sangue da mãe durante a gestação, inibe o desenvolvimento de enzimas necessárias para a síntese de lactose até pouco tempo antes do parto (FRANDSON et al., 2011).

Diversas pesquisas vêm buscando formas de aproveitar o colostro e o leite de transição excedente para a alimentação das bezerras até o momento do desmame. O colostro pode ser estocado à temperatura ambiente em regiões de clima frio. No entanto, quando o colostro é armazenado em alta temperatura ambiental, o risco de perdas e da presença de contaminantes é elevado (AZEVEDO \& DUARTE, 2014). Nesse caso, aditivos químicos têm sido usados para controlar a fermentação (TAHMASBI et al., 2014).

SAALFELD (2008) desenvolveu uma forma de conservar o colostro por meio de fermentação anaeróbica, técnica conhecida como silagem de colostro. Em seus trabalhos concluiu que a silagem de colostro não necessita de refrigeração, congelamento ou aditivos, o que contribui para o seu baixo custo de elaboração. Essa metodologia consiste no armazenamento do colostro em garrafas plásticas de politereftalato de etilenotipo (PET), hermeticamente vedadas, por um período mínimo de 21 dias.

Os diferentes modos de processamento e estocagem do colostro e do leite de transição podem interferir na composição do produto final e devem visar a produção de um alimento seguro para os bezerros. As características físicas e microbiológicas da silagem devem ser consideradas, pois o odor, a consistência e o $\mathrm{pH}$ podem refletir a qualidade microbiológica do produto fermentado (AZEVEDO \& DUARTE, 2014).

Sabe-se que o processo de fermentação inativa bactérias patogênicas. WRAY \& CALLOW (1974) citado por AZEVEDO \& DUARTE, (2014) afirmaram que o 
uso de colostro fermentado como substituto do leite não favorece a ocorrência de salmonelose ou colibacilose nos bezerros, pois, normalmente, produtos acondicionados e fermentados de forma adequada não permitem a sobrevivência de agentes da família Enterobacteriaceae em concentrações suficientes para promover alterações intestinais nos bezerros.

Silagens com fermentação inadequada apresentam pH elevado e podem representar risco de contaminação por microrganismos patogênicos ou deteriorantes para os animais (AZEVEDO et al., 2014a); além de reduzir o tempo de estocagem e a qualidade proteica do alimento (AZEVEDO \& DUARTE, 2014).

A silagem mantém os valores de proteína, matéria seca e gordura do colostro in natura. Entretanto, há uma visível diminuição no teor de lactose (SAALFELD et al., 2013). Esse evento ocorre porque a lactose é o principal nutriente consumido pelas bactérias ácido-láticas que se desenvolvem rapidamente em condição anaeróbica (BATISTA et al., 2016). O valor de pH diminui após sete dias de fermentação, em decorrência da produção de ácido lático (SAALFELD et al., 2013).

O dia de obtenção da secreção láctea das vacas doadoras influencia a qualidade da silagem. AZEVEDO et al. (2014a) demonstraram que a fermentação in vitro do colostro de segunda ordenha resultou em alta taxa de perdas e valores de $\mathrm{pH}$ insuficientes para conservar apropriadamente o produto, apresentando altas contagens de Enterobaceriaceae e Staphylococcus spp. Resultados semelhantes foram relatados por BATISTA et al. (2016). No experimento desses pesquisadores, a silagem derivada do colostro da primeira ordenha após o parto não permitiu armazenamento por longos períodos, pois manifestou ampla contaminação por enterobactérias, fungos e leveduras. $\mathrm{O}$ pH decresceu, mas não atingiu o valor ideal de 4,0 para uma silagem de qualidade. Com 15 dias de fermentação, houve diminuição da população microbiana porque houve redução do principal substrato utilizado, a lactose.

Por outro lado, a fermentação do leite de transição apresentou boa taxa de aproveitamento, pois mostrou elevada concentração de Lactobacillus spp. e ausência de Enterobacteriaceae, Staphylococcus spp. e fungos, sendo indicada para o processo de conservação (AZEVEDO et al., 2014a).

O tempo de fermentação também é importante. As presenças de bactérias Lactobacillus spp., Staphylococcus spp., Escherichia spp., Klebsiella spp e Bacillus spp. e levedura Candida spp. foram observadas no colostro e na silagem de colostro (primeiro e segundo dias após o parto) até 14 dias de fermentação. Já com 21 dias de fermentação, foram isolados somente Lactobacillus spp. (SAALFELD et al., 2013). O isolamento único de Lactobacillus spp. e pH com valores lineares decrescentes são indicativos de um processo fermentativo e conservativo de boa qualidade (AZEVEDO et al., 2014a).

A diarreia neonatal é uma das principais causas de morte em bezerros nas fazendas de leite e resulta em altas perdas econômicas para o setor (UETAKE, 2013). A diarreia pode ser observada após a administração de colostro fermentado, sendo atribuída, principalmente, ao excesso de acidez $(\mathrm{pH}<4,0)$, em função do longo período de estocagem. Uma alternativa para evitar a acidez excessiva da silagem de colostro ou leite de transição, o que pode comprometer a aceitação do produto, é o acréscimo de bicarbonato de sódio como agente tamponante (MANCIO et al., 2005a; MANCIO et al., 2005b). 
A notificação de diarreia após consumo de colostro ou leite fermentado não é unanimidade entre os autores. FERREIRA et al. (2013) identificaram fezes anormais e secas na segunda semana de vida dos bezerros que receberam silagem de colostro oriundo da segunda e terceira ordenha pós-parto. Em contrapartida, AZEVEDO et al. (2013) relataram média de 6,70 dias de diarreia considerando os grupos estudados (leite integral, silagem de leite de transição dissolvida em leite e silagem de leite de transição dissolvida em água), no período que se estendeu do $6^{\circ}$ ao $59^{\circ}$ dia de vida dos bezerros.

Além das características físico-químicas e microbianas, um outro aspecto de fundamental importância para caracterizar a silagem de colostro e leite de transição como alimento, é o desempenho animal. Diversas pesquisas foram realizadas comparando-se a administração de leite integral, sucedâneo lácteo comercial ou silagem de colostro/ leite de transição, diluída em água ou leite, e o efeito dessas dietas líquidas na performance de bezerros. Os resultados variam muito e as principais pesquisas estão apresentadas a seguir.

Alguns experimentos (CASTRO et al., 2004a; CASTRO et al., 2004b; MANCIO et al., 2005a; MANCIO et al., 2005b) compararam o fornecimento de leite integral e colostro fermentado (das primeiras ordenhas após a parição), com ou sem a adição de óleo de soja e com ou sem a aplicação de um implante subcutâneo contendo $36 \mathrm{mg}$ de zeranol em quarenta bezerros mestiços (Holandês $x$ Zebu). $\mathrm{O}$ zeranol é um anabolizante sintetizado a partir da zearalenona, extraída do fungo de milho. Esse composto age como um promotor de crescimento, pois aumenta a porcentagem de proteína e diminui os teores de gordura na carcaça (MANCIO et al., 2005b). O óleo foi adicionado para suprir uma possível deficiência energética do colostro fermentado, por possuir menores níveis de lactose.

CASTRO et al. (2004a) concluíram que não é necessário adicionar o óleo ao colostro fermentado para incrementar o nível energético, uma vez que a dieta com esse alimento proporcionou melhores resultados de peso corporal e ganho de peso quando comparada à dieta com leite integral. Também promoveu maior consumo de matéria seca, o que resultou em desempenho semelhante para os dois tipos de alimentos (leite integral e colostro fermentado). O colostro fermentado foi considerado uma boa opção para a recria de machos inteiros.

MANCIO et al. (2005a) consideraram a silagem de colostro uma fonte nutricional adequada para o crescimento de bezerros pré-ruminantes, podendo ser empregada para substituir o leite integral. $O$ colostro fermentado sem zeranol resultou em carcaças $5 \%$ mais pesadas em relação às carcaças dos animais alimentados com leite integral sem zeranol. $O$ desempenho (pesos de carcaça quente e fria) dos animais do tratamento colostro + zeranol foi igual ao dos animais nutridos com leite + zeranol. Animais tratados com leite apresentaram maiores proporções de osso e gordura na carcaça.

Os bezerros submetidos aos dois tipos de dieta líquida (leite integral e colostro fermentado) apresentaram taxas de crescimento constantes e similares, demonstrando que o colostro fermentado é capaz de promover ganhos de peso da mesma intensidade que o leite integral. O grupo que recebeu colostro fermentado ainda demonstrou maior consumo de ração concentrada e, consequentemente, de matéria seca e proteína bruta que o leite integral (MANCIO et al., 2005a).

Outros trabalhos avaliaram a diluição (na proporção de 1:1) da silagem de colostro ou leite de transição em água ou leite, no momento da oferta aos bezerros. 
Para AZEVEDO et al. (2013), a administração de silagem de leite de transição misturada à água ou ao leite não mudou o consumo total de matéria seca pelos animais; entretanto menor ganho de peso foi verificado em animais aleitados com silagem diluída em água. Houve semelhança de ganhos de peso entre os animais que receberam leite integral ou silagem misturada ao leite. Os autores destacaram que a diluição da silagem em leite integral proporciona resultados de desempenho semelhantes ao dos animais que receberam unicamente o leite in natura, o que possibilita menor custo por quilo de peso vivo (AZEVEDO et al., 2013). Em outra pesquisa publicada em 2014, o mesmo grupo de pesquisa ressaltou que a silagem misturada ao leite proporcionou dados mais próximos ao suprimento exclusivo de leite integral, validando-se como possibilidade para a nutrição de bovinos jovens (AZEVEDO et al., 2014b).

Além do mais, a avaliação dos órgãos internos evidenciou que a silagem de leite de transição diluída em água afetou negativamente o desempenho dos bezerros, resultando na diminuição do peso das vísceras e de gordura interna (omental) (AZEVEDO et al., 2014b).

VIRGINIO Jr. et al. (2016) avaliaram o fornecimento de 4 litros dia ${ }^{-1}$ de leite ou silagem de leite de transição ( $3^{\circ}$ ao $6^{\circ}$ dia pós-parto), diluída na proporção de 1:1 em leite e 1:1 em água em 18 bezerros Holandeses, no período de seis a 59 dias de idade. Realizaram a eutanásia dos animais ao término do experimento e análises em $15 \mathrm{~mL}$ do conteúdo ruminal, abomaso e em $10 \mathrm{~g}$ de fezes. Não houve influência do sistema de amamentação na cor, odor e viscosidade do líquido ruminal. Os aleitamentos com silagem de leite de transição em água ou leite não influenciaram as características físico-químicas $(\mathrm{pH})$ e microbianas (presença de bactérias da família Enterobacteriaceae, fungos micelianos e leveduras nos diferentes sítios do trato digestório), concordando com estudos que indicam que esse produto pode ser usado como sucedâneo lácteo na criação de terneiros leiteiros.

Em contrapartida, o uso da silagem de colostro (segunda e terceira ordenhas) como dieta líquida exclusiva em 18 bezerros da raça Holandesa não resultou em desempenho animal adequado, pois diminuiu o consumo de concentrado, o ganho médio diário e o peso vivo em comparação ao sucedâneo lácteo comercial ofertado no mesmo volume diário de quatro litros (FERREIRA et al., 2013). Para os autores, o colostro apresentou boa conservação em condições anaeróbicas, mas houve rejeição do consumo, perda de peso e prejuízo na saúde dos animais durante as quatro primeiras semanas após o nascimento. Desta maneira, os autores não indicaram a silagem de colostro como dieta líquida exclusiva para bezerros em aleitamento.

No estudo pioneiro de SAALFELD (2008), concluiu-se que os animais alimentados com silagem de colostro obtiveram ganho de peso superior ao observado em animais alimentados com leite, constituindo-se assim, num alimento viável para a utilização como sucedâneo do leite.

SAALFELD et al. (2013) avaliaram o ganho de peso de 31 bezerros da raça Holandesa, de ambos os sexos, divididos em dois grupos experimentais: leite integral (controle; $n=17$ ) e silagem de colostro (tratamento; $n=14$ ). A silagem de colostro (primeiro e segundo dias pós-parto) foi diluída em água e ofertada no volume de 4,5 $\mathrm{L} \mathrm{dia}^{-1}$ quando os animais tinham de 4 a 14 dias de vida e $3,5 \mathrm{~L} \mathrm{dia}^{-1}$ na idade de 15 a 60 dias. O grupo tratado exibiu ganho médio diário superior $(700 \mathrm{~g}$ $\mathrm{dia}^{-1}$ para fêmeas e machos) quando comparado ao grupo controle (600 g dia ${ }^{-1}$ para fêmeas e machos). 
TAHMASBI et al. (2014) usaram 40 bezerros neonatos da raça Holandesa, sendo 20 machos e 20 fêmeas, em um período experimental de 42 dias. Os animais foram alimentados com o colostro de suas mães, duas vezes ao dia (1,5 a 2,0 kg por refeição), nos primeiros dois dias de vida. No terceiro dia, se iniciou o experimento e os animais foram divididos em quatro tratamentos, nos quais eram oferecidas duas fontes proteicas diferentes associadas a duas dietas líquidas distintas: farelo de soja e farinha de carne e ossos com colostro fresco ou naturalmente fermentado.

Os colostros utilizados na pesquisa foram colhidos nas primeiras oito ordenhas após o parto, acidificados com ácido fórmico e armazenados em containers plásticos de 60 ou 120 litros de capacidade. O ácido fórmico foi diluído (uma parte de ácido fórmico para 10 partes de água) e, então, $25 \mathrm{~mL}$ desta diluição foi acrescida por quilo de dieta líquida. Uma parte do colostro fermentado com ácido fórmico foi misturada com duas partes de água no momento do fornecimento para que o colostro fermentado e o leite fresco apresentassem conteúdo similar de sólidos totais, gordura, proteína e lactose. Foram fornecidos dois quilos de dieta líquida por refeição.

O sexo e a dieta líquida não representaram efeito significativo na ingestão de alimento, porém os bezerros consumiram mais no tratamento contendo farelo de soja $(15 \pm 0,2 \mathrm{~kg})$ do que no tratamento contendo farinha de osso e carne $(13 \pm 0,2$ $\mathrm{kg}$ ), durante o período experimental. Já o ganho de peso, tamanho corporal (incluindo altura de cernelha, altura de garupa, comprimento de garupa e largura de garupa) e o tamanho do estômago foram influenciados pela dieta líquida, sendo superiores na dieta com leite fresco. O ganho de peso foi diferente apenas nas primeiras três semanas do estudo e, segundo os autores, este fato pode ser explicado pelo consumo de leite fresco ter sido maior $(10,4 \mathrm{~kg})$ em relação ao consumo de colostro fermentado $(9,77 \mathrm{~kg})$ e também porque a diluição em água no momento do fornecimento diminuiu a qualidade nutricional, por diminuir a porcentagem de sólidos totais do produto final.

Em um estudo recente, SOUZA et al. (2016) realizaram uma análise metaanalítica com 16 pesquisas de sete estados brasileiros, que abrangeu 51 dietas (leite integral, sucedâneo lácteo e silagem de colostro) e 485 bezerros. O peso vivo inicial médio foi de $37,5 \pm 4,35 \mathrm{~kg}$ e peso final médio foi de $62,0 \pm 10,16 \mathrm{~kg}$. O estudo mostrou que uma dieta com leite integral representou ganho médio diário, do nascimento à desmama, superior $\left(477 \mathrm{~g} \mathrm{dia}^{-1}\right)$ às outras dietas que empregaram substitutos ao leite $\left(379 \mathrm{~g} \mathrm{dia}^{-1}\right)$.

Como ficou evidenciado pelos relatos acima, as conclusões dos experimentos são contraditórias e variáveis, o que pode ser devido à composição nutricional do colostro ou do leite de transição utilizados para a fermentação, assim como as condições higiênicas de confecção e armazenamento diferentes em cada trabalho. Isto posto, está claro que existe um espaço importante para novas pesquisas, ainda mais se considerar que o emprego da silagem de colostro/leite de transição representa uma grande economia para a cadeia leiteira.

A análise econômica de três dietas líquidas apontou que o emprego da silagem diluída em água ou misturada ao leite reduziu o custo total da nutrição de bezerras, em $86,19 \%$ e $43,87 \%$, respectivamente, em comparação ao aleitamento com leite (AZEVEDO et al., 2013).

Ademais, o menor custo verificado com animais alimentados com colostro fermentado viabiliza o seu uso como alternativa para o aproveitamento dos machos em rebanho leiteiro. CASTRO et al. (2004b) consideraram que as menores 
despesas associadas a um satisfatório desempenho obtido, demonstraram que o colostro fermentado é eficiente como substituto do leite para bezerros em fase de aleitamento, gerando maior lucratividade.

Um aspecto interessante que deve ser considerado é o uso da silagem de colostro como maneira de conservar imunoglobulinas com qualidade para a transferência de imunidade passiva aos bezerros. SAALFELD et al. (2014) divulgaram que a silagem de colostro mantém níveis similares de imunoglobulinas viáveis, e estas podem ser transferidas para bezerros recém-nascidos em quantidades semelhantes às observadas com a ingestão do colostro in natura, oferecendo uma boa proteção imunológica.

Atualmente, existe uma preocupação pertinente da comunidade científica com o crescimento e o conforto das bezerras leiteiras durante as fases de cria e recria e como o desenvolvimento das bezerras neste período reflete na histologia do parênquima mamário e, consequentemente, na produtividade futura. Para HULBERT \& MOISÁ (2016), tecnologias de alojamento e de manejo alimentar de bezerros devem ser melhoradas e desenvolvidas e é necessário aumentar o conhecimento sobre a imunocompetência e a resiliência de animais jovens.

Pesquisas futuras considerando as condições de ordenha e saúde das vacas doadoras do colostro ou do leite de transição, assim como o acréscimo de conservantes e inoculantes, serão importantes para manter o material conservado de forma segura (AZEVEDO \& DUARTE, 2014), produção de um produto de boas características nutricionais e sustentar essa tecnologia como aleitamento alternativo de bezerros. O menor custo verificado com animais nutridos com colostro ou leite de transição fermentado é um precedente para que novos experimentos sejam realizados nesta área.

\section{CONSIDERAÇÕES FINAIS}

A silagem de colostro ou leite de transição é o resultado de um processo fermentativo, em condição de anaerobiose, que usa o excesso de secreção láctea das vacas após o parto, sem valor industrial, porém com valor nutricional, para conservar e prover um substituto do leite para bezerros. No entanto, se a fermentação for inadequada, pode resultar em um produto com alta taxa de descarte e elevada concentração de microrganismos patogênicos, prejudicando a saúde dos bezerros. Os estudos que avaliaram o desempenho animal ainda mostram resultados contraditórios e variáveis, em comparação às outras dietas líquidas (leite integral e sucedâneo lácteo comercial), mas há um indicativo de superioridade quando a silagem é diluída em leite e não em água. A economia dos custos na criação de bezerras é um bom precedente para que novos estudos sejam realizados.

\section{REFERÊNCIAS}

ANDRADE, E. A.; ANSELMI, R.; MENDES, C. Q. Silagem de colostro: alternativa sustentável para a bovinocultura leiteira. SB Rural - Caderno Rural, n. 49, 2010. Disponível em: http://www.ceo.udesc.br/arquivos/id_submenu/285/caderno_udesc_049.pdf>

AZEVEDO, R. A. de; ARAÚJO, L.; COELHO, S.G.; FARIA FILHO, D.R. de; DUARTE, E.R.; GERASEEV, L.C. Desempenho de bezerros alimentados com silagem de leite de transição. Pesq. Agropec. Bras., Brasília, v. 48, n. 5, p. 545-552, 
2013. Disponível em: < http://dx.doi.org/10.1590/50100-204X201300500011>. doi: 10.1590/50100-204X201300500011

AZEVEDO, R. A. de; DUARTE, E. R. Aspectos microbiológicos do colostro bovino em diferentes técnicas de conservação e armazenamento: uma revisão. REDVET Rev. Electrón. Vet., Montes Claros, v. 15, n. 6, p. 84-98, 2014. Disponível em: <http://www.veterinaria.org/revistas/redvet/n060614/061402.pdf>

AZEVEDO, R.A. de; GUIMARÃES, F.; VIEGAS, C.R.; ALMEIDA, P.N.M. de; GERASEEV, L.C.; PINTO, M.S.; GLÓRIA, J.R. da; DUARTE, E.R. Silagem de colostro: riscos microbiológicos e caracterização do $\mathrm{pH}$ em função do dia de coleta. Rev. Bras. Med. Vet., v. 36, n. 3, p. 271-276, 2014a. Disponível em: < http://www.rbmv.com.br/pdf_artigos/16-12-2014_15-12RBMV053.pdf>

AZEVEDO, R. A. de; DUARTE, D.V.L.; SOARES, A.L.M.; OLIVEIRA, N.J.F.; COELHO, S.G.; DUARTE, E.R.; GERASEEV, L.C. Desenvolvimento de bezerros leiteiros alimentados com silagem de leite de transição. II - Órgãos internos. Arq. Bras. Med. Vet. Zootec., v. 66, n. 2, p. 505-509, 2014b. Disponível em: <http://dx.doi.org/10.1590/1678-41626624>. doi: 10.1590/1678-41626624

AZEVEDO, R.A. de; COELHO, S.G. Efeito dos programas de nutrição, do nascimento até a puberdade sobre o desenvolvimento mamário de novilhas leiteiras. Nutri Time Revista Eletrônica, v. 13, n. 5, p. 4794-4799, 2016. Disponível em: <http://www.nutritime.com.br/arquivos_internos/artigos/Artigo_390.pdf>

BATISTA, G.N.; MOREIRA, P.S.A.; OLIVEIRA, L.T.; ROSA, C.C.B.; POLIZEL NETO, A. Avaliação do tempo de armazenamento e composição da silagem de colostro entre duas raças leiteiras: Girolando e Jersey. Sci. Elec. Arch., v. 9, n. 2, p. 10-16, 2016. Disponível em: http://www.seasinop.com.br/revista/index.php?journal=SEA\&page=article\&op=view\& path\%5B\%5D=222\&path\%5B\%5D=pdf_85>

CASTRO, A.L.M.; CAMPOS, W.E.; MANCIO, A.B.; PEREIRA, J.C.; CECON, P.R. Desempenho e rendimento de carcaça de bezerros alimentados com colostro fermentado, associado ao óleo de soja e zeranol. Arq. Bras. Med. Vet. Zootec., v. 56, n. 2, p. 193-201, 2004a. Disponível em: < http://dx.doi.org/10.1590/S010209352004000200009 >. doi: $10.1590 /$ S010209352004000200009

CASTRO, A.L.M.; CAMPOS, W.E.; MANCIO, A.B.; CAMPOS, O.F. Avaliação econômica de bezerros alimentados com colostro fermentado, associado ao óleo de soja e zeranol. Arq. Bras. Med. Vet. Zootec., v. 56, n. 2, p. 202-206, 2004b. Disponível em: <http://dx.doi.org/10.1590/S0102-09352004000200010>. doi: $10.1590 /$ S0102-09352004000200010

CONNEELY, M.; BERRY, D.P.; MURPHY, J.P.; LORENZ, I.; DOHERTY, M.L.; KENNEDY, E; Effect of feeding colostrum at different volumes and subsequent number of transition milk feeds on the serum immunoglobulin $G$ concentration and 
health status of dairy calves. J. Dairy Sci., v. 97, p. 6991-7000, 2014. Disponível em: http://dx.doi.org/10.3168/jds.2013-7494. doi: 10.3168/jds.2013-7494

FERREIRA, L.S.; BITTAR, C.M.M.; SILVA, J.T.; SOARES, M.C.; OLTRAMARI, C.E.; NÁPOLES, G.G.O.; PAULA, M.R. Desempenho e parâmetros sanguíneos de bezerros leiteiros que receberam sucedâneo lácteo ou silagem de colostro. Arq. Bras. Med. Vet. Zootec., v. 65, n. 5, p.1357-1366, 2013. Disponível em: < http://dx.doi.org/10.1590/S0102-09352013000500013>. doi: 10.1590/S010209352013000500013

FRANDSON, R.D.; WILKE, W. L.; FAILS, A.D. In: Anatomia e fisiologia dos animais de fazenda. 7. ed. Rio de Janeiro: Guanabara Koogan, 2011. 413p.

GODDEN, S. Colostrum management for dairy calves. Vet. Clin. North. Am. Food Anim. Pract., v. 24, n. 1, p.19-39, 2008. Disponível em: < http://dx.doi.org/10.116/j.cvfa.2007.1005>. doi: 10.116/j.cvfa.2007.1005

HULBERT, L.E.; MOISÁ, S.J. Stress, immunity and management of calves. J. Dairy Sci., v. 99, p. 1-18, 2016. Disponível em: < http://dx.doi.org/10.3168/jds. 201510198>. doi: 10.3168/jds. 2015-10198

KHAN, M.A.; BACH, A.; WEARY, D.M.; von KEYSERLINGK, M.A.G. Invited review: transitioning from milk to solid feed in dairy heifers. J. Dairy Sci., v. 99, p. 1-18, 2016. Disponível em: <http://dx.doi.org/10.3168/jds.2015-9975>. doi: 10.3168/jds.2015-9975

LUIZ, D. J; SIMÕES, B. N; TAMOSTU, S. R; CASALE, A. A. L; SANTANA, E. H. W de. Avaliação físico-química e microbiológica do leite UHT comercializado em três países do Mercosul (Brasil, Argentina e Paraguai). Arch. Latinoam. Nutr., v. 60, n. 3, p. 261-269, 2010. Disponível em: http://www.scielo.org.ve/scielo.php?script=sci_arttext\&pid=S000406222010000300008>

MALDONADO, N.C.; NADER-MACIAS, M.E.F. Production of fermented milk with autochthonous Lactobacilli for newborn calves and resistance to the dairy farm conditions. J. Bioprocess., v. 6, n. 4, p. 1-5, 2016. Disponível em: < http: //dx.doi.org/10.4172-9821.1000278>. doi: 10.4172/2155-9821.1000278

MANCIO, A.B.; GOES, R.H.T.B. de; CASTRO, A.L.M.; CAMPOS, O.F.; CECON, P.R.; SILVA, A.T.S. da. Colostro fermentado, associado ao óleo de soja e promotor de crescimento, em substituição ao leite, na alimentação de bezerros mestiços leiteiros. R. Bras. Zootec., v. 34, n. 4, p. 1314-1319, 2005a. Disponível em: < http://www.scielo.br/pdf/\%0D/rbz/v34n4/26403.pdf>

MANCIO, A.B.; GOES, R.H.T.B. de; CASTRO, A.L.M.; CECON, P.R.; SILVA, A.T.S. da. Características de carcaça de bezerros de rebanhos leiteiros desmamados precocemente e alimentados com diferentes dietas líquidas. R. Bras. Zootec., v. 34, n. $4, \quad$ p. 1297-1304, 2005b. Disponível em: < http://www.scielo.br/pdf/\%0D/rbz/v34n4/26401.pdf> 
MURRAY, C.F.; LESLIE, K.E. Newborn calf vitality: risk factors, characteristics, assessment resulting outcomes and strategies for improvement. Vet. J., v. 198, n. 2, p. 322-328, 2013. Disponível em: < http://dx.doi.org/10.1016/j.tvjl.2013.06.007>. doi: 10.1016/j.tvjl.2013.06.007

NASCIMENTO, G.V.; CARDOSO, E.A.; BATISTA, N.L.; de SOUZA, B.B.; CAMBUÍ, G.B. Indicadores produtivos, fisiológicos e comportamentais de vacas de leite. ACSA, v. 9, n. 4, p. 28-36, 2013. Disponível em: <http://150.165.111.246/ojspatos/index.php/ACSA >

OLIVEIRA, E. N. A. de; SANTOS, D. C. da; OLIVEIRA, A. S. da; SOUSA, F. C. de. Composição físico-química de leites em diferentes fases de lactação. Rev. Acad., Ciênc. Agrár. Ambient., Curitiba, v. 8, n. 4, p. 409-415, 2010. Disponível em: $<$ www2.pucpr.br/reol/index.php/ACADEMICA?dd1=4512\&dd99=pdf>

ROA, I.; SMOK, C.S.; PRIETO, R.G. Placenta: anatomía e histología comparada. Int. J. Morphol., v. 30, n. 4, p. 1490-1496, 2012. Disponível em: <http://dx.doi.org/10.4067/S0717-95022012000400036>.

doi: 10.4067/S0717-95022012000400036

SAALFELD, M. H. Uso da silagem de colostro como substituto do leite na alimentação de terneiras leiteiras. A Hora Veterinária, v. 162, p. 59-62, 2008. Disponível

em:

http://www.scielo.br/scielo.php?script=sci_nlinks\&ref=000088\&pid=S0102-

0935201400020002600016\&lng=en>

SAALFELD, M. H.; PEREIRA, D.I.B.; SILVEIRA, K.R.K.; SCHRAMM, R.; VALENTE, J.S.S.; BORCHARDT, J.L.; GULARTE, M.A.; LEITE, F.P.L. Anaerobically fermented colostrum: an alternative for feeding calves. Ciência Rural, v. 43, n. 9, p.1636-1641, 2013. Disponível em: < http://dx.doi.org/10.1590/S0103-84782013000900016>. doi: 0.1590/S0103-84782013000900016

SAALFELD, M.H.; PEREIRA, D.I.B.; BORCHARDT, J.L.; STURBELLE, R.T.; ROSA, M.C.; GUEDES, M.C.; GULARTE, M.A.; LEITE, F.P.L. Evaluation of the transfer of immunoglobulin from colostrum anaerobic fermentation (colostrum silage) to newborn calves. Anim. Sci. J., v. 85, n. 11, p. 963-967, 2014. Disponível em: < http://onlinelibrary. wiley.com/doi/10.1111/asj.12229/abstract;jsessionid=25E07633B5 A6036C9D054B04E90A5603.f04t03. doi: 10.1111/asj.12229

SILPER, B. F; COELHO, S. G; MADEIRA, M. M. F; RUAS, J. R. M; LANA, A. M. Q; REIS, R. B; SATURNINO, H. M. Avaliação da qualidade do colostro e transferência de imunidade passiva em animais mestiços Holandês Zebu. Arq. Bras. Med. Vet. Zootec, v. 64, n. 2, p. 281-285, 2012. Disponível em: < http://dx.doi.org/10.1590/S0102-09352012000200005 >. doi: 10.1590/S010209352012000200005

SOUZA, V.L.; DRACKLEY, J.K.; ALMEIDA, R.; BITTAR, C.M.M.; ALBERTINI, T.Z.; MORRISON, S.Y. LANNA, P.D. Evaluation of nutrition models to estimate 
performance of young dairy calves: a meta-analytical study under tropical conditions. Animal, p. $\quad 1-10,2016.2$ Disponível em: < http://dx.doi.org/10.1017/S1751731116000975>. doi: 10.1017/S1751731116000975

TAHMASBI, A.M.; ABADI, S.H.J.; NASERIAN, A.A. the effect of two liquid feeds and two sources of protein in starter on performance and blood metabolites in Holstein neonatal calves. J. Dairy Sci., v. 97, p. 363-371, 2014. Disponível em: http://dx.doi.org/10.3168/jds.2012-6356. doi: 10.3168/jds.2012-6356

UETAKE, K. Newborn calf welfare: a review focusing on mortality rates. Anim. Sci. J., v. 84, n. 2, p. 101-105, 2013. Disponível em: http://onlinelibrary.wiley.com/doi/10.1111/asj.12019/full. doi: 10.1111/asj.12019

VIRGINIO JÚNIOR, G.F.; DUARTE, E.R.; ORNELAS, L.T.C.; AZEVEDO, R.A. de; PINTO, M.S.; GERASEEV, L.C. Caracterização físico-química e microbiológica do fluido ruminal e do conteúdo gastrointestinal de bezerros alimentados com silagem de leite de transição. Agrária, Recife, v.11, n.2, p.142-147, 2016. Disponível em: < http://www.agraria.pro.br/ojs-2.4.6/index.php?journal=agraria\&page=article\&op= view\&path\%5B\%5D=agraria_v11i2a5367\&path\%5B\%5D=4903>.doi:10.5039/agraria. v11i2a5367

WATTIAUX, M. A. Heifer raising - birth to weaning. Importance of colostrum feeding. In: WATTIAUX, M. A. Dairy Essentials. Madson: Instituto Babcok, University of Wisconsin, p. 109-112, 1997. 